Research Article

\title{
Shear Characteristics of Cement-Stabilized Sand Reinforced with Waste Polyester Fiber Fabric Blocks
}

\author{
Xiangfeng $\operatorname{Lv} \mathbb{i D}^{1,2}$ and Hongyuan Zhou ${ }^{3}$ \\ ${ }^{1}$ School of Civil and Resource Engineering, University of Science and Technology Beijing, Beijing 100083, China \\ ${ }^{2}$ Beijing Key Laboratory of Urban Underground Space Engineering, University of Science and Technology Beijing, \\ Beijing 100083, China \\ ${ }^{3}$ School of Resources and Civil Engineering, Northeastern University, Shenyang 110000, China \\ Correspondence should be addressed to Xiangfeng Lv; szgcyjylvxiangfeng@163.com
}

Received 5 May 2019; Accepted 1 July 2019; Published 10 July 2019

Academic Editor: Shazim A. Memon

Copyright (c) 2019 Xiangfeng Lv and Hongyuan Zhou. This is an open access article distributed under the Creative Commons Attribution License, which permits unrestricted use, distribution, and reproduction in any medium, provided the original work is properly cited.

\begin{abstract}
The present paper is devoted to investigate the effects of waste polyester fiber fabric blocks on the strength and mechanical behavior of cemented sand. In the investigation, samples were prepared at four different percentages of waste polyester fiber fabric block content $(0.0 \%, 0.5 \%, 1.0 \%$, and $1.5 \%$ by weight of soil) and two different aspect ratios $(2: 1$ and $3: 1)$, and conventional triaxial compression tests were carried out after the curing period. The test results indicated that the addition of fibers increased peak and residual shear strengths of cemented sand and changed its brittle behavior to a more ductile one. As the fabric block content increased, the brittleness index and initial stiffness decreased, and the peak strain and internal friction angle increased. The optimal combination of the content and aspect ratio was determined to be $0.5 \%$ and $3: 1$. The integration of the fabric blocks with the cemented sand matrix was analyzed by using the scanning electron microscopy (SEM). It is found that the reinforcement effect is related to the bond strength and friction at the interface. The micromechanical properties of the fiber/matrix interface were influenced by the undulations between the fabric block components. In summary, this study presented a low-cost and environment-friendly method for reinforcing cement-stabilized sand.
\end{abstract}

\section{Introduction}

Chemically reinforced cement has been shown to significantly improve the mechanical properties of soil and is hence widely used in soft soil foundation treatment, backfilling of retaining walls, roadbed reinforcement of roads and railways, etc. $[1-3]$. However, cement-stabilized soil does not exhibit significant plastic deformation. Moreover, it is prone to brittle fracture, which can adversely affect the safety and stability of engineering projects.

To overcome the above problems, some researchers incorporated fiber materials into cement-stabilized soils [4-13]. They found that the addition of fiber materials could improve the unconfined compressive strength, shear strength, residual shear strength, and postpeak stress loss of cement-stabilized soil, thereby making the soil ductile to a certain extent. At present, widely used fibers in engineering mainly include polypropylene fiber, glass fiber, carbon fiber, and basalt fiber [14]. The use of chemical fibers will inevitably result in environmental pollution. Therefore, the reinforcement of cement-stabilized soil using fibers or blocks obtained from waste materials has emerged as a hot research topic in the field of geotechnical engineering, and related studies have been conducted by several researchers. Chen et al. [15] used fiber blocks obtained from waste polypropylene fiber bags to reinforce cement-stabilized sand, and they studied the effects of fiber content, fiber length, and curing age on the unconfined compressive strength of cement-stabilized sand. Similarly, Estabragh et al. [16] used nylon fibers to reinforce cement-stabilized clay, and they studied the effects of fiber content, cement content, and curing age on the unconfined compressive strength of 
cement-stabilized clay. In particular, they showed that nylon fibers could not only increase the unconfined compressive strength and peak strain of cement-stabilized clay but also facilitate a transition from brittle failure to ductile failure. Mirzababaei et al. [17] used waste carpet fibers to reinforce clay, and they conducted tests to prove that the fibers could significantly improve the unconfined compressive strength, reduce the attenuation rate of the postpeak strength, and increase the ductility of clay. Cao et al. [18] used cotton fiber blocks (length, $12 \mathrm{~mm}$; width, $5 \mathrm{~mm}$ ) and polyester fiber blocks (length, $12 \mathrm{~mm}$; width, $5 \mathrm{~mm}$ ) obtained from waste clothes to reinforce clay. By conducting the cutting-ringbased penetration test, California bearing ratio (CBR) test, and direct shear test, they found that both types of fiber blocks could significantly improve the shear strength and bearing capacity of clay.

According to incomplete statistics, between 2011 and 2015 , the cumulative production of waste fiber fabrics in China reached 140 million tons; however, the recycling rate was less than $10 \%$. Proper disposal and recycling of waste fiber fabrics have emerged as critical issues from the viewpoint of environmental protection in China [19]. Toward this end, the use of waste textile fabrics to reinforce cement-stabilized soil can not only solve engineering problems but also provide significant environmental and economic benefits. However, only a few studies have reported the use of waste fiber fabrics to reinforce cementstabilized soil. Moreover, fewer studies have reported the use of such fabrics to reinforce cement-stabilized sand.

In the present study, waste polyester fiber fabric blocks were used to reinforce cement-stabilized sand. A triaxial test was conducted to study the effects of the waste polyester fiber fabric blocks on the shear characteristics of cement-stabilized sand. Furthermore, the corresponding reinforcement mechanism was analyzed via the scanning electron microscopy.

\section{Experimental Schemes}

2.1. Test Materials. Noncohesive fine sand is used in this study. It is sampled from the construction site of an integrated pipe gallery in Yanqing District, Beijing, China. Table 1 provides the basic physical parameters of sand. Table 2 provides the components of the sand. The particlesize distribution is shown in Figure 1.

The cement used in the experiment was Portland II Cement, Type II, which mainly consisted of $3 \mathrm{CaO} \cdot \mathrm{SiO}_{2}$, $2 \mathrm{CaO} \cdot \mathrm{SiO}_{2}, 3 \mathrm{CaO} \cdot \mathrm{Al}_{2} \mathrm{O}_{3}$, and $4 \mathrm{CaO} \cdot \mathrm{Al}_{2} \mathrm{O}_{3} \cdot \mathrm{Fe}_{2} \mathrm{O}_{3}$. The cement had a specific gravity of 3.08 and a water-cement ratio of 0.485 . The cement had a 7 -day compressive strength of 19.2 MPa, a tensile strength of $1.6 \mathrm{MPa}$, a 28 -day compressive strength of $42.5 \mathrm{MPa}$, and a tensile strength of 2.22 MPa [20-23].

The waste polyester fabric blocks were cut from discarded sportswear (95\% polyester) using a fiber cutting machine. Two sizes of the fabric blocks were considered, i.e., $6 \mathrm{~mm} \times 3 \mathrm{~mm}$ and $9 \mathrm{~mm} \times 3 \mathrm{~mm}$, with aspect ratios of $2: 1$ and $3: 1$, respectively. The block thickness was $0.041 \mathrm{~mm}$. Furthermore, the waste polyester fiber had a monofilament diameter of $20.84 \mathrm{~mm}$, a relative density of 1.15 , a water absorption ratio of $14.1 \%$, and an elongation ratio of $6.4 \%$. According to $[24,25]$ measurements, the tensile strength and the elastic modulus of the monofilament were determined to be $355 \mathrm{MPa}$ and $2250 \mathrm{MPa}$, respectively.

\subsection{Triaxial Test Method}

2.2.1. Test Parameters and Sample Preparation. In this study, the following contents of waste polyester fiber fabric blocks were $0.0 \%, 0.5 \%, 1.0 \%$, and $1.5 \%$. The cement content was determined to be $3.0 \%$, the water content was $15.7 \%$, the relative density was 0.70 , and the curing time was 7 days.

The samples were prepared using a split mold $39.1 \mathrm{~mm}$ in diameter. Samples prepared for triaxial tests were $80.0 \mathrm{~mm}$ in height and were compacted in eight layers. Each layer was poured into the mold and compacted using a metal hammer until the desired height was reached [26]. Once prepared, the sample was cured in a concrete curing box at a temperature of $25 \pm 2^{\circ} \mathrm{C}$ and humidity above $90 \%$ for seven days [27]. After the curing was completed, the sample was dried in a drying oven at a temperature of $50^{\circ} \mathrm{C}$. The drying was stopped when the change in the sample mass was less than $0.01 \mathrm{~g}$.

2.2.2. Apparatus and Test Parameters. A full-automatic strain-controlled triaxial test apparatus was used to perform the triaxial test. The test was carried out under confining pressures of $100 \mathrm{kPa}, 300 \mathrm{kPa}$, and $500 \mathrm{kPa}$ and a shear rate of $0.8 \mathrm{~mm} / \mathrm{min}$ [28]. The shear strength was determined on the basis of the previous study [29].

2.3. Scanning Electron Microscope Experiment. Three types of samples, namely, cement-stabilized sand, cement-stabilized sand reinforced with waste polyester fiber fabric blocks, and waste polyester fiber fabric blocks, were analyzed. While preparing the cement-stabilized sand sample, the sand was first made into a $3 \mathrm{~cm} \times 3 \mathrm{~cm} \times 3 \mathrm{~cm}$ cube, followed by air drying; then, it was cut into a $5 \mathrm{~mm} \times 5 \mathrm{~mm} \times 5 \mathrm{~mm}$ sample for the experiment. The sample of cement-stabilized sand reinforced with waste polyester fiber fabric blocks was obtained from the sample failure surface after the triaxial test. During the sampling process, a $1 \mathrm{~cm} \times 1 \mathrm{~cm} \times 1 \mathrm{~cm}$ cube was first made and then air-dried and cut into a $5 \mathrm{~mm} \times 5 \mathrm{~mm} \times 5 \mathrm{~mm}$ sample for the experiment. The waste polyester fiber fabric block was used directly for the scanning electron microscopy experiment. The gold sputtering step was skipped during the experiment to minimize the disturbance to the sample.

\section{Test Results and Analysis}

The triaxial test results are summarized in Table 3, where the shear strength was the peak point of the stress-strain curve, and the residual shear strength was the axial stress when the axial strain reached $16 \%$. 
TABLE 1: Basic physical parameters of sand.

\begin{tabular}{lccccccc}
\hline$\rho_{\mathrm{d}, \max }\left(\mathrm{g} \cdot \mathrm{cm}^{3}\right)$ & $\rho_{\mathrm{d}, \min }\left(\mathrm{g} \cdot \mathrm{cm}^{3}\right)$ & $e_{\max }$ & $e_{\min }$ & $G_{\mathrm{s}}$ & $\omega_{\mathrm{p}}(\%)$ & $C_{\mathrm{u}}$ & $C_{\mathrm{c}}$ \\
\hline 1.82 & 1.59 & 0.73 & 0.48 & 2.74 & 15.7 & 2.25 & 0.92 \\
\hline
\end{tabular}

TABle 2: Components of the sand.

\begin{tabular}{lcccccc}
\hline $\mathrm{SiO}_{2}(\%)$ & $\mathrm{AlO}_{2}(\%)$ & $\mathrm{CaO}(\%)$ & $\mathrm{K}_{2} \mathrm{O}(\%)$ & $\mathrm{Na}_{2} \mathrm{O}(\%)$ & $\mathrm{Fe}_{2} \mathrm{O}_{3}(\%)$ & $\mathrm{TiO}_{2}(\%)$ \\
\hline 74.25 & 15.20 & 1.51 & 5.25 & 1.92 & 1.25 & 0.62 \\
\hline
\end{tabular}

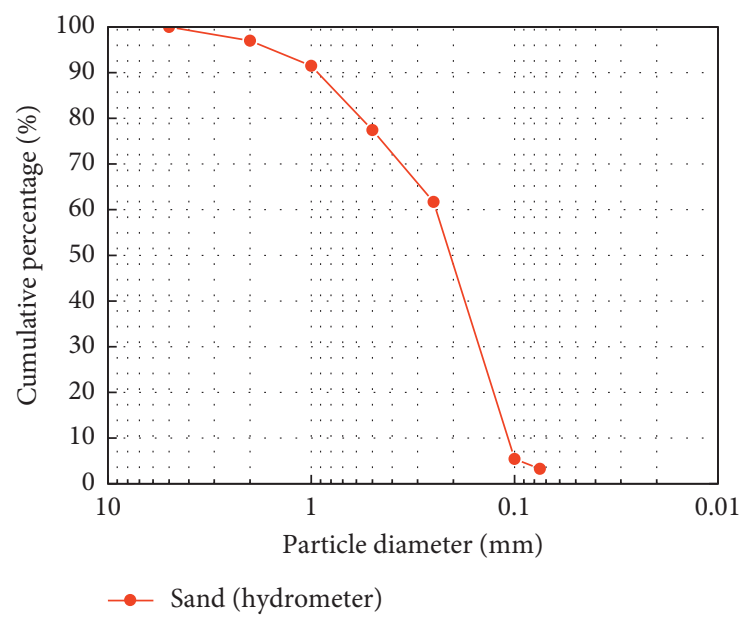

Figure 1: Particle-size distribution of sand.

TABLE 3: Summary of triaxial test results.

\begin{tabular}{|c|c|c|c|c|c|c|}
\hline \multirow{2}{*}{$\mathrm{AR}$} & \multirow{2}{*}{ FC (\%) } & \multirow{2}{*}{ Confining pressure $(\mathrm{kPa})$} & \multicolumn{2}{|c|}{ Shear strength $(\mathrm{kPa})$} & \multicolumn{2}{|c|}{ Axial strain (\%) } \\
\hline & & & At failure & In residual state & At failure & In residual state \\
\hline 0 & 0 & 100 & 1064.5 & 433.8 & 2.625 & 16.0 \\
\hline 0 & 0 & 300 & 1543.2 & 853.4 & 3.1875 & 16.0 \\
\hline 0 & 0 & 500 & 1981.0 & 1305.5 & 3.375 & 16.0 \\
\hline $2: 1$ & 0.5 & 100 & 1269.5 & 731.2 & 3.00 & 16.0 \\
\hline $2: 1$ & 0.5 & 300 & 1905.7 & 1198.8 & 3.625 & 16.0 \\
\hline $2: 1$ & 0.5 & 500 & 2473.7 & 1868.8 & 4.25 & 16.0 \\
\hline $2: 1$ & 1.0 & 100 & 1310.6 & 823.7 & 4.00 & 16.0 \\
\hline $2: 1$ & 1.0 & 300 & 2008.3 & 1493.2 & 4.25 & 16.0 \\
\hline $2: 1$ & 1.0 & 500 & 2563.3 & 2243.9 & 4.75 & 16.0 \\
\hline $2: 1$ & 1.5 & 100 & 1355.5 & 900.1 & 4.25 & 16.0 \\
\hline $2: 1$ & 1.5 & 300 & 2043.1 & 1539.2 & 5.25 & 16.0 \\
\hline $2: 1$ & 1.5 & 500 & 2578.7 & 2259.9 & 5.75 & 16.0 \\
\hline $3: 1$ & 0.5 & 100 & 1689.0 & 864.7 & 2.4375 & 16.0 \\
\hline $3: 1$ & 0.5 & 300 & 2240.4 & 1504.2 & 3.375 & 16.0 \\
\hline $3: 1$ & 0.5 & 500 & 2821.6 & 2240.5 & 3.5625 & 16.0 \\
\hline $3: 1$ & 1.0 & 100 & 1357.5 & 800.8 & 2.8125 & 16.0 \\
\hline $3: 1$ & 1.0 & 300 & 2161.4 & 1486.1 & 3.5625 & 16.0 \\
\hline $3: 1$ & 1.0 & 500 & 2693.5 & 2225.9 & 3.5625 & 16.0 \\
\hline $3: 1$ & 1.5 & 100 & 1175.3 & 740.2 & 3.375 & 16.0 \\
\hline $3: 1$ & 1.5 & 300 & 2006.6 & 1388.5 & 4.5625 & 16.0 \\
\hline $3: 1$ & 1.5 & 500 & 2690.1 & 2154.6 & 5.50 & 16.0 \\
\hline
\end{tabular}

AR: aspect ratio; FC: polyester fabric block content.

3.1. Characteristics of the Stress-Strain Curve. The stressstrain curves of the cement-stabilized sand and the cementstabilized sand reinforced with waste polyester fiber fabric blocks are shown in Figures 2(a)-2(g). A comparison of Figures 2(a)-2(g) shows that fiber inclusion enhanced the peak stress of cemented sand, but the contributions of further 

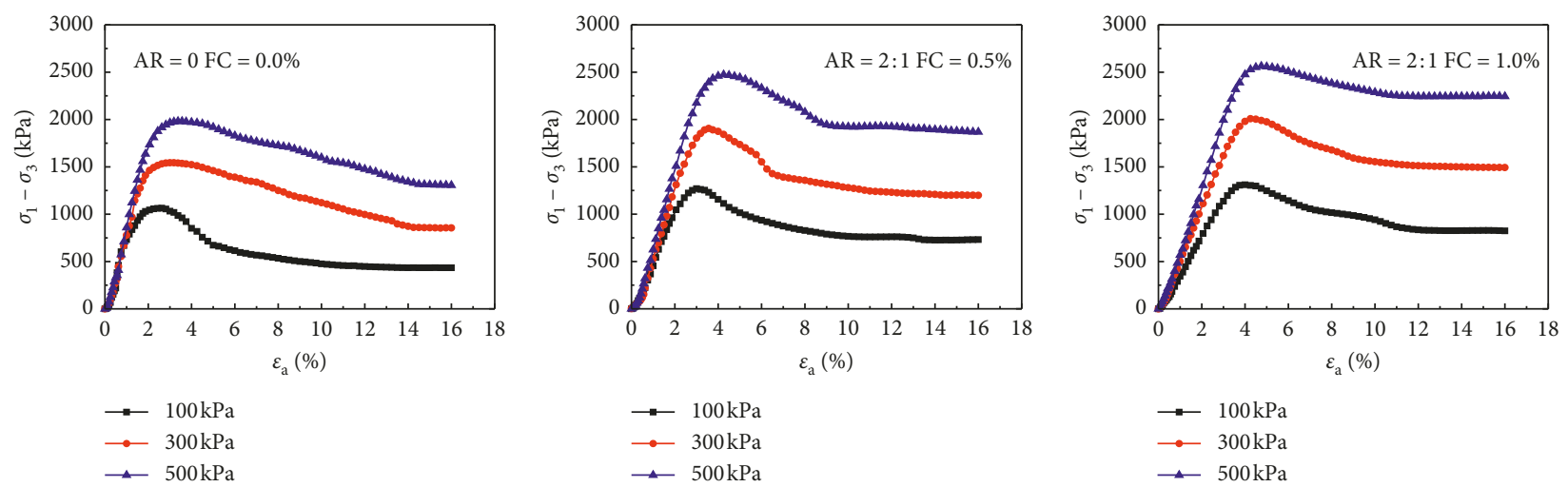

$\longrightarrow \quad 100 \mathrm{kPa}$
$\longrightarrow \quad 300 \mathrm{kPa}$
$\longleftarrow 500 \mathrm{kPa}$

$\longrightarrow$
$\longrightarrow \quad 300 \mathrm{kPa}$

$\simeq 500 \mathrm{kPa}$

(a)

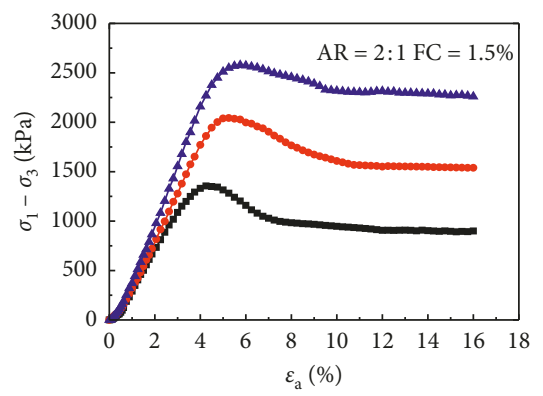

(b)

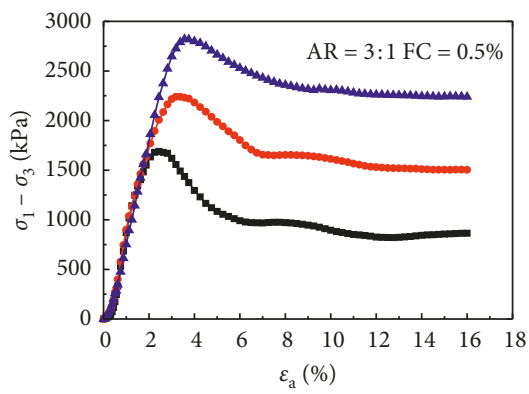

(c)

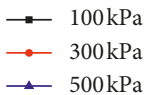

$\rightarrow-100 \mathrm{kPa}$

$\rightarrow 300 \mathrm{kPa}$

$\simeq 500 \mathrm{kPa}$

(e)

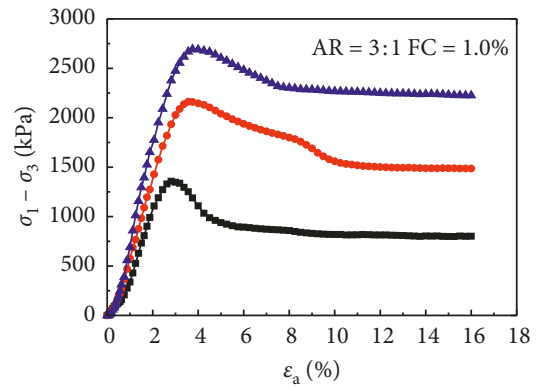

(d)

$$
\begin{aligned}
& \longrightarrow 100 \mathrm{kPa} \\
& \longrightarrow 300 \mathrm{kPa} \\
& \simeq 500 \mathrm{kPa}
\end{aligned}
$$

(f)

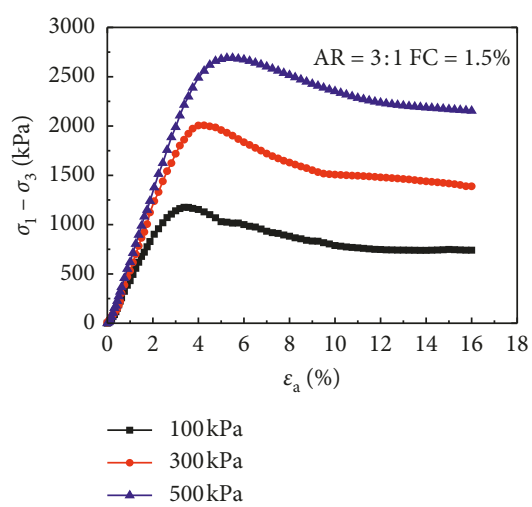

(g)

FIgURE 2: Stress-strain curves of triaxial samples.

increase of fiber content to peak stress was insignificant. It can also be seen that fiber-reinforced cemented sand exhibits more ductile behavior and smaller loss of postpeak strength than cemented sand. The reduction in the loss of postpeak stress is more pronounced for higher fiber content. In addition, the failure strain of fiber-reinforced cemented sand is much smaller than that of cemented sand. These observations indicate that the waste polyester fiber fabric blocks can effectively improve the cement-stabilized sand's shearing behavior.

3.2. Variations in Shear Strength and Peak Strain under the Effects of Content and Aspect Ratio. The variations in shear strength and peak strain under the effects of content and aspect ratio are shown in Figure 3. As can be seen from Figure 3(a), when the aspect ratio was $2: 1$, the bulk content and shear strength increased; by contrast, when the aspect ratio was $3: 1$, the shear strength first increased and then decreased. When the content and aspect ratio were constant, the shear strength increased with increasing confining pressure. When the aspect ratio was $3: 1$ and the content was $0.5 \%$, the shear strength attained its peak value, i.e., $1689.0 \mathrm{kPa}, 2240.4 \mathrm{kPa}$, and $2821.6 \mathrm{kPa}$. Compared with the cement-stabilized sand, these peak values increased by $58.7 \%, 45.2 \%$, and $42.4 \%$, respectively. As can be seen from Figure 3(b), when the content increased, the strain at failure 


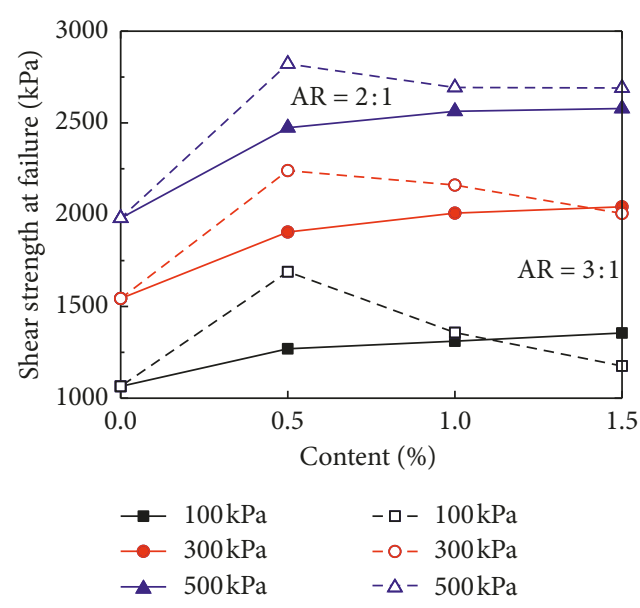

(a)

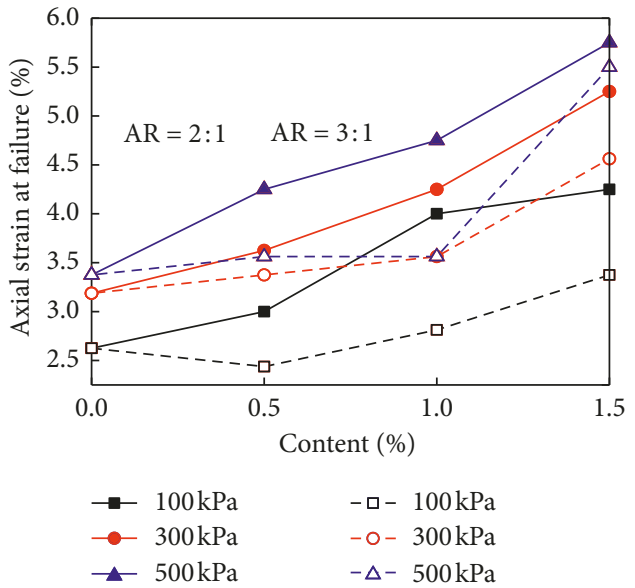

(b)

FIGURE 3: Variations in (a) shear strength and (b) peak strain under the effects of fabric block content and aspect ratio.

increased and the ductility was enhanced. Under the same conditions, when the aspect ratio was $2: 1$, the sample strain at failure was larger, i.e., $4.25 \%, 5.25 \%$, and $5.75 \%$, respectively. Compared with the cement-stabilized sand, the strain at failure increased by $61.9 \%, 64.7 \%$, and $70.4 \%$, respectively.

\subsection{Variations in Residual Shear Strength under the Effects of} Content and Aspect Ratio. The variations in residual shear strength under the effects of content and aspect ratio are shown in Figure 4. It can be seen that when the aspect ratio was $2: 1$, the residual shear strength increased with increasing block content; by contrast, when the aspect ratio was $3: 1$, the residual shear strength first increased and then decreased. When the aspect ratio was 3:1 and the content was $0.5 \%$, the residual shear strength attained its peak value, i.e., $864.7 \mathrm{kPa}, 1504.2 \mathrm{kPa}$, and $2240.5 \mathrm{kPa}$, respectively. Compared with the cement-stabilized sand, these peak values increased by $99.3 \%, 76.2 \%$, and $71.6 \%$, respectively. These results indicate that the variations in shear strength and residual strength were similar under the effects of content and aspect ratio. Both attained their peak values under the same content and aspect ratio $(0.5 \%$ and $3: 1$, respectively). Therefore, this combination of content and aspect ratio could be defined as the optimal combination.

\subsection{Variations in Brittleness Index under the Effects of Content} and Aspect Ratio. As a brittle material, cement-stabilized sand does not undergo plastic deformation easily and is prone to brittle fracture under external load. The brittleness index proposed by Consoli et al. [30] was introduced to quantitatively analyze the brittleness and ductility of cement-stabilized sand reinforced with waste polyester fiber fabric blocks. It is given by the following equation:

$$
I_{\mathrm{B}}=\frac{q_{\mathrm{max}}}{q_{\mathrm{res}}}-1
$$

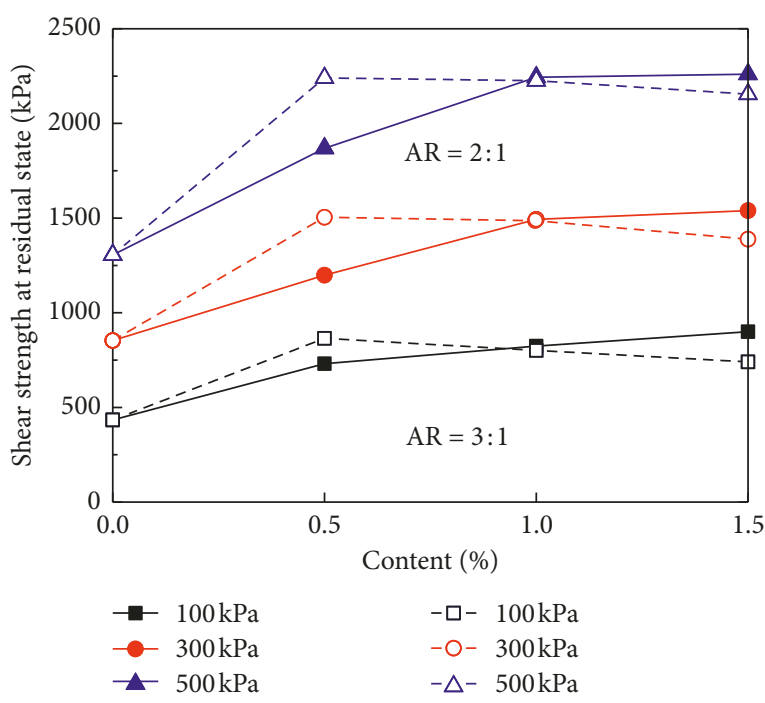

FIGURE 4: Variations in residual strength under the effects of fabric block content and aspect ratio.

where $q_{\max }$ is the shear strength and $q_{\text {res }}$ is the residual shear strength. As can be seen from Figure 5, the brittleness index of cement-stabilized sand decreased after adding the waste polyester fiber. When the content and aspect ratio were constant, the brittleness index decreased with increasing confining pressure. When the confining pressure and aspect ratio were constant, the brittleness index decreased with increasing block content. When the confining pressure was $100 \mathrm{kPa}$, the brittleness index decreased as the aspect ratio increased (from $2: 1$ to $3: 1$ ). Furthermore, when the confining pressure was $300 \mathrm{kPa}$ or $500 \mathrm{kPa}$ and the content was $0.5 \%$, the brittleness index decreased with increasing aspect ratio; by contrast, when the content was $1.0 \%$ and $1.5 \%$, the brittleness index increased with increasing aspect ratio. From the above analysis, it can be concluded that the effects aspect ratio on the brittleness index was related to the confining pressure and content. 


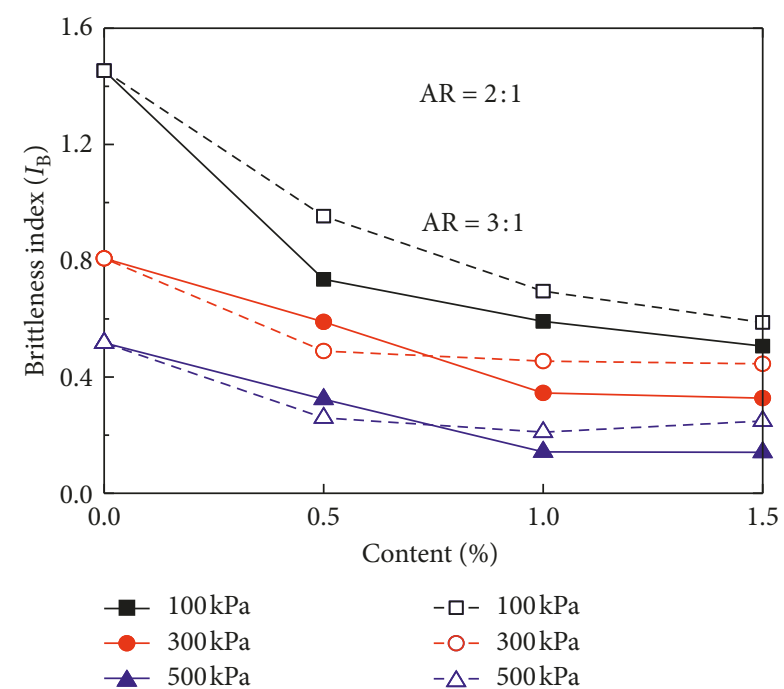

FIGURE 5: Variations in brittleness index under the effects of fabric block content and aspect ratio.

3.5. Variations in Stiffness at 50\% Shear Strength (E50) under the Effects of Content and Aspect Ratio. Stiffness (E50) is defined as the ratio of the stress at half of the peak strength to the corresponding strain. It reflects the ability of the sample to resist deformation under external load. The variations in stiffness under the effects of content and aspect ratio are shown in Figure 6. It can be seen that, after adding the blocks, the stiffness of cement-stabilized sand decreased. When the content and aspect ratio were constant, the stiffness decreased with increasing confining pressure. When the aspect ratio and confining pressure were constant, the stiffness decreased with increasing content. Furthermore, when the content and confining pressure were constant, the stiffness increased with increasing aspect ratio. The variation in stiffness was consistent with that observed in the study by Hamidi and Hooresfand [9].

3.6. Variations in Energy Absorption Capacity under the Effects of Content and Aspect Ratio. The variations in the energy absorption capacity under the effects of content and aspect ratio are shown in Figure 7. It can be seen that, after adding waste polyester fiber fabric blocks, the energy absorption capacity of cement-stabilized sand increased, indicating that the energy required for deformation and the resistance of the sample to deformation increased. When the content and aspect ratio were constant, the energy absorption capacity increased with increasing confining pressure. When the confining pressure was constant and the aspect ratio was $2: 1$, the energy absorption capacity increased with increasing content, and when the aspect ratio was $3: 1$, the energy absorption capacity decreased with increasing content. When the content and confining pressure were constant, the overall energy absorption capacity increased with increasing aspect ratio. Furthermore, when the aspect ratio was $3: 1$ and the content was $0.5 \%$, the energy absorption capacities under the three confining pressures were $158.3 \mathrm{~kJ} / \mathrm{m}^{3}, 257.3 \mathrm{~kJ} / \mathrm{m}^{3}$, and $345.3 \mathrm{~kJ} / \mathrm{m}^{3}$, respectively. Compared with cement-stabilized

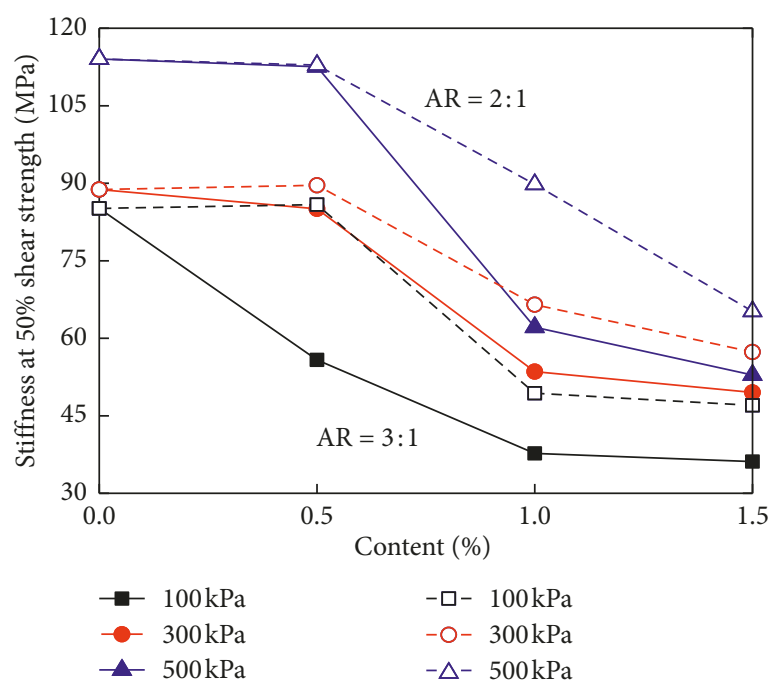

FIgURE 6: Variations in stiffness under the effects of fabric block content and aspect ratio.

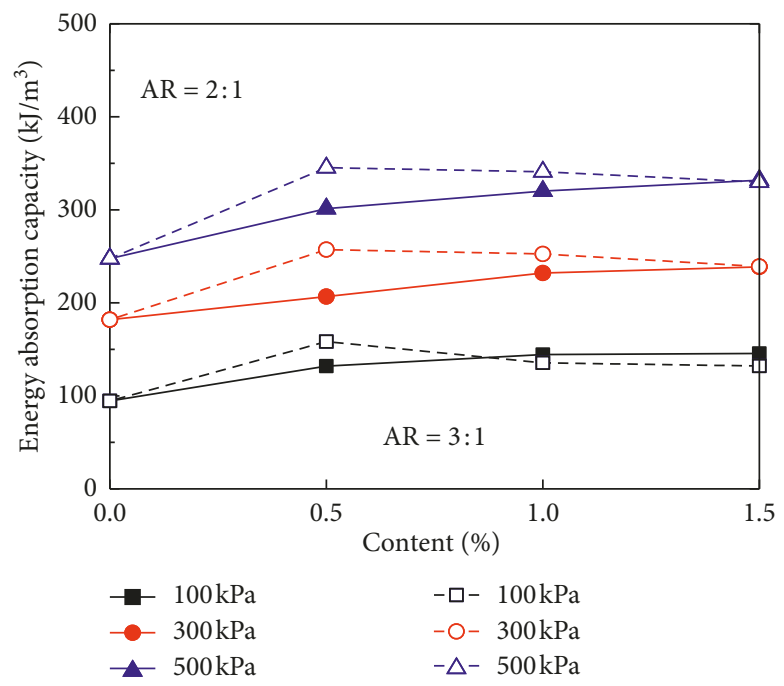

FIgURE 7: Variations in energy absorption capacity under the effects of fabric block content and aspect ratio.

sand, the energy absorption capacity increased by $67.5 \%$, $41.5 \%$, and $39.5 \%$, respectively. From the above analysis, it can be concluded that the effects of confining pressure and aspect ratio on the energy absorption capacity were relatively independent of other factors, whereas the effect of content on the energy absorption ratio was related to the aspect ratio.

\subsection{Variations in Cohesion and Internal Friction Angle under} the Effects of Content and Aspect Ratio. The shear strength envelope of cement-stabilized sand reinforced with the waste polyester fiber is shown in Figure 8. The variations in cohesion and internal friction angle under the effects of content and aspect ratio are shown in Figure 9. It can be seen that when the aspect ratio was $2: 1$, the cohesion and internal friction angle increased with increasing content. When the content was $1.5 \%$, the cohesion increased from 


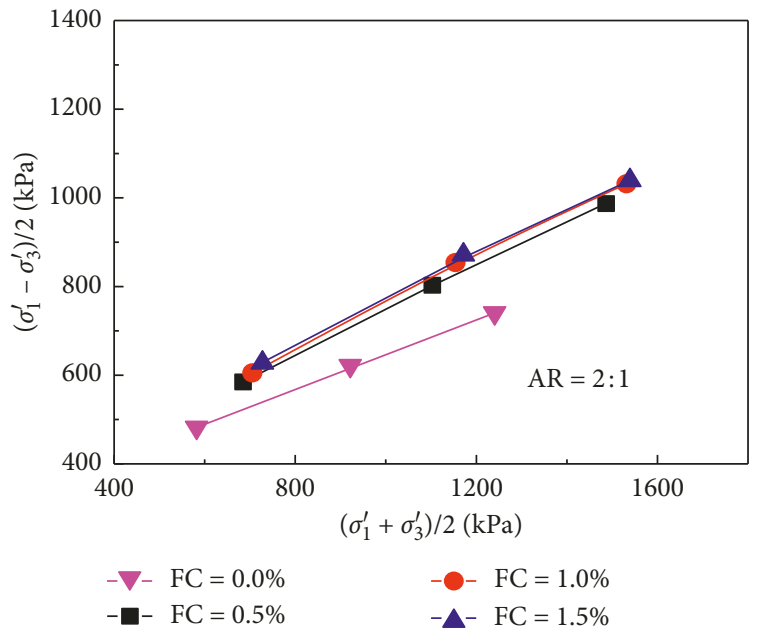

(a)

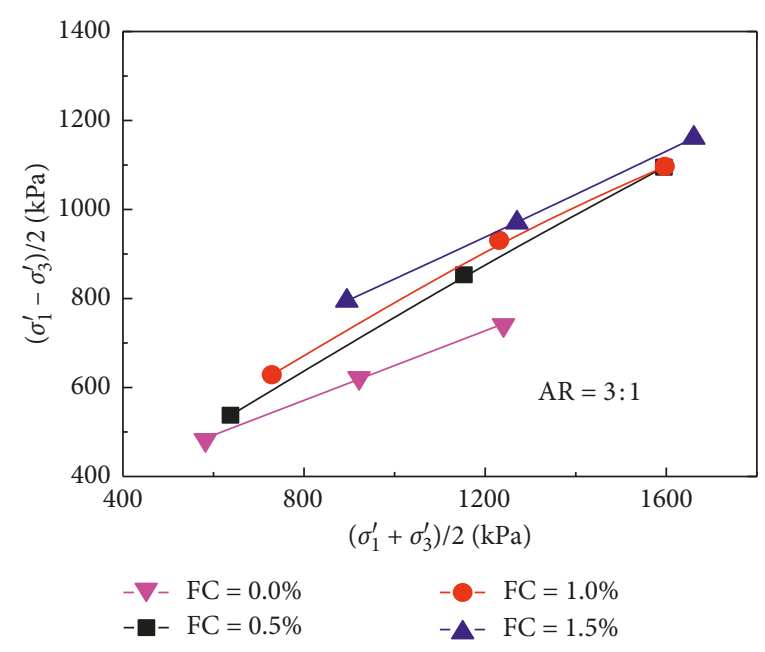

(b)

Figure 8: Shear strength envelope: (a) aspect ratio of $2: 1$; (b) aspect ratio of $3: 1$.

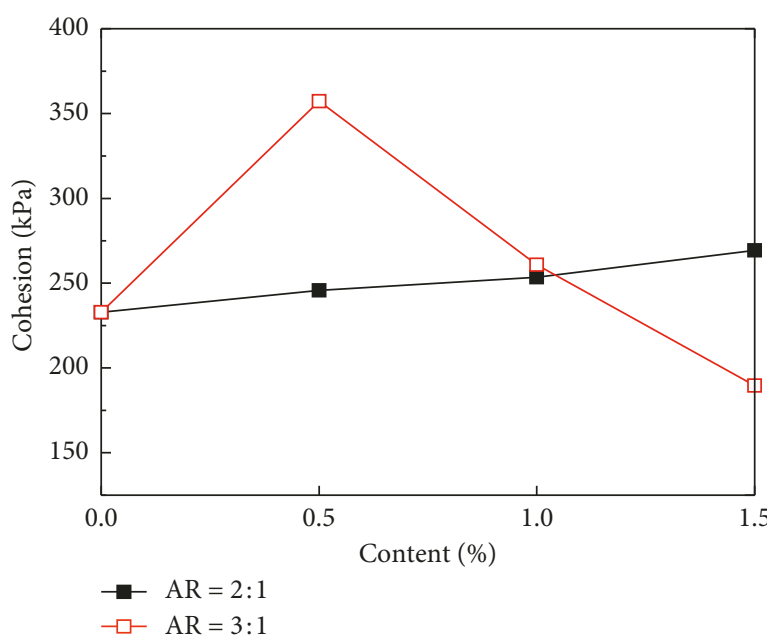

(a)

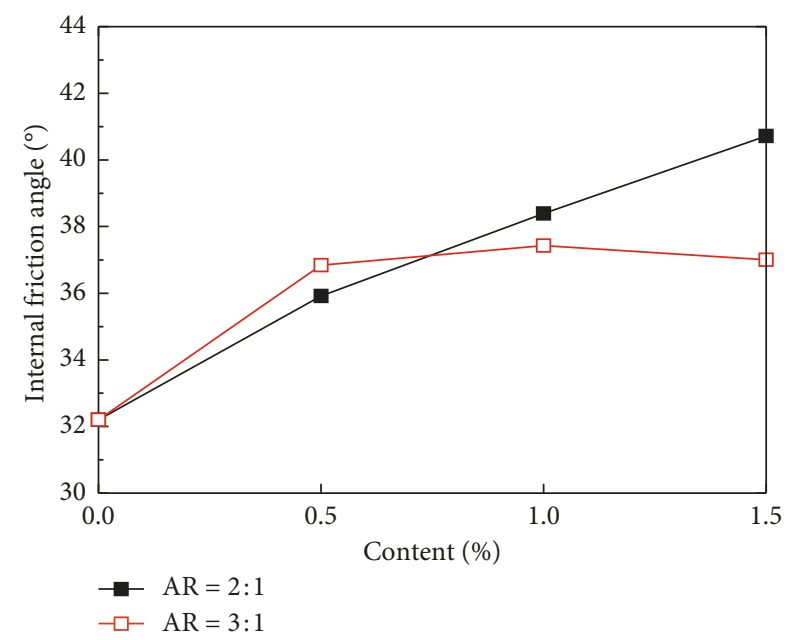

(b)

FIGURE 9: Variations in cohesion and internal friction angle under the effects of content and aspect ratio: (a) aspect ratio of $2: 1$; (b) aspect ratio of $3: 1$.

$232.87 \mathrm{kPa}$ to $269.41 \mathrm{kPa}$, and the extent of increase was $15.7 \%$. When the aspect ratio was $3: 1$, as the content increased, the cohesion first increased and then decreased, and the internal friction angle continued to increase. When the content was $0.5 \%$, the cohesion increased from $232.87 \mathrm{kPa}$ to $357.23 \mathrm{kPa}$, and the extent of increase was $53.4 \%$. When the content was $1.5 \%$, the cohesion was $189.63 \mathrm{kPa}$, which was less than that of cement-stabilized sand $(232.87 \mathrm{kPa})$. These results indicate that, under the optimal combination of content and aspect ratio $(0.5 \%$ and $3: 1$, respectively), the fabric blocks could fully reinforce the cement-stabilized sand, whereas, under the nonoptimal combinations, the fabric blocks could reduce the strength of cement-stabilized sand.
3.8. Variations in Residual Cohesion and Residual Internal Friction Angle under the Effects of Content and Aspect Ratio. The residual shear strength envelope of cement-stabilized sand reinforced with waste polyester fiber fabric blocks is shown in Figure 10. The variations in the residual cohesion and residual internal friction angle are shown in Figure 11. It can be seen that, after the fabric blocks were added, the residual cohesion and residual internal friction angle of cement-stabilized sand increased, indicating that the fabric blocks could reinforce the postpeak shear performance of cement-stabilized sand. When the aspect ratio was $2: 1$, the residual cohesion increased with increasing content. When the content was $1.5 \%$, the residual cohesion increased from $58.60 \mathrm{kPa}$ to $129.26 \mathrm{kPa}$, and the extent of increase was 


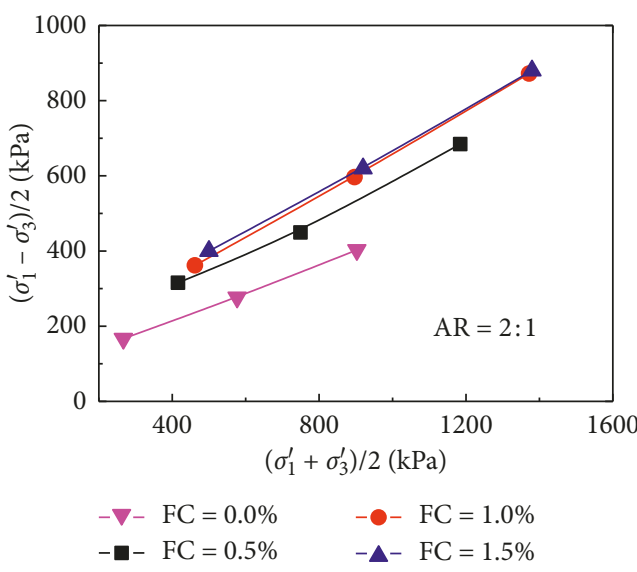

(a)

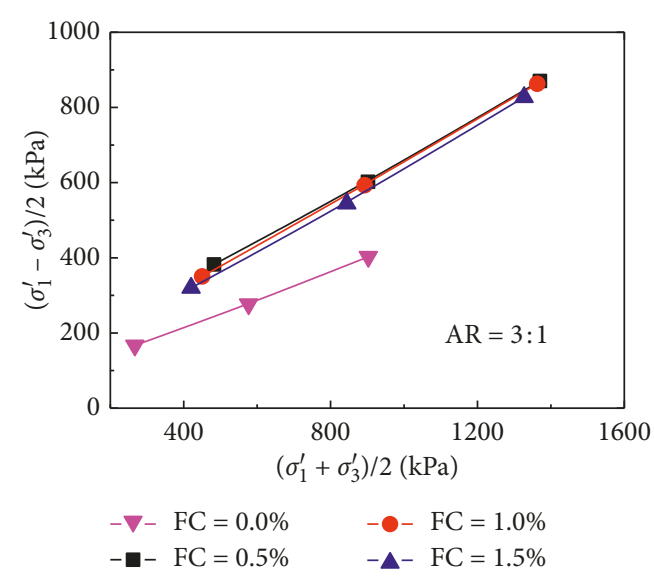

(b)

Figure 10: Residual shear strength envelope: (a) aspect ratio of $2: 1$; (b) aspect ratio of $3: 1$.

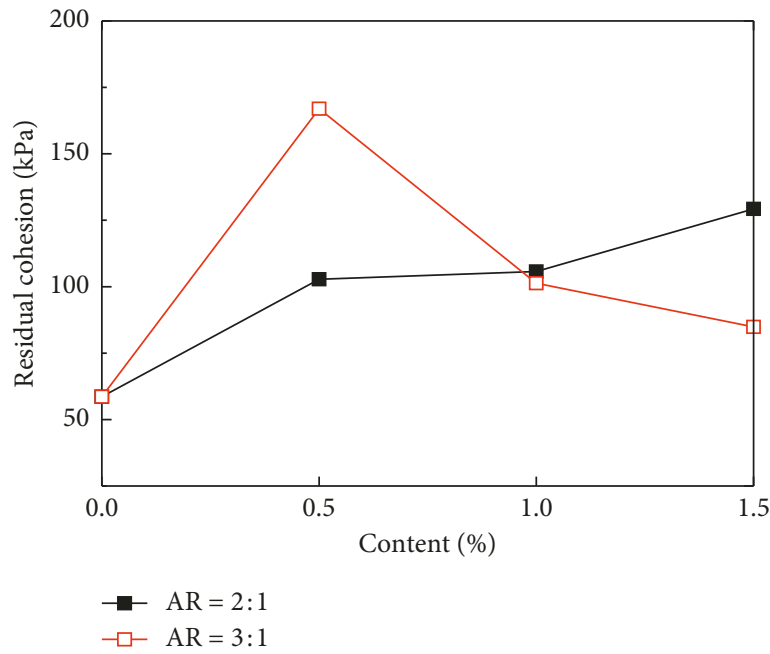

(a)

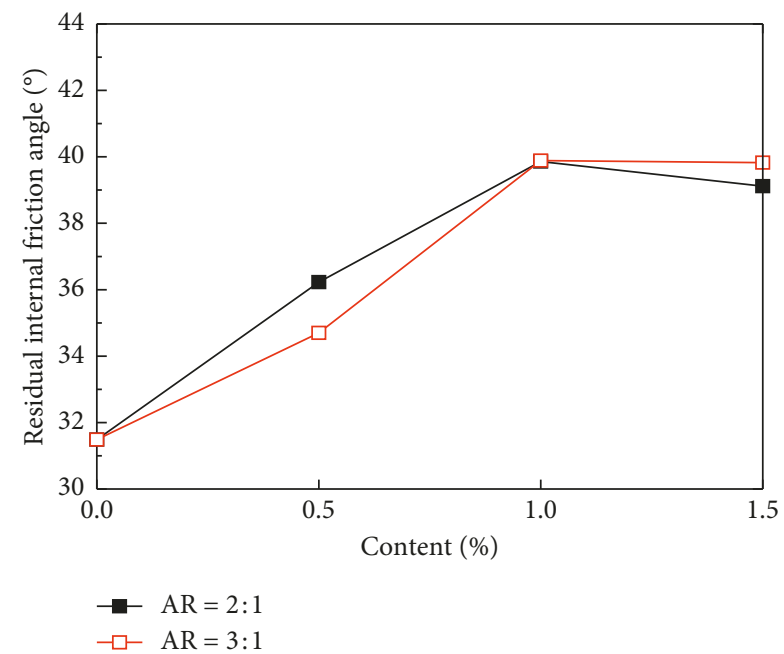

(b)

FIGURE 11: Variations in residual cohesion and residual internal friction angle under the effects of content and aspect ratio: (a) aspect ratio of $2: 1$; (b) aspect ratio of $3: 1$.

$120.6 \%$. When the aspect ratio was $3: 1$, as the content increased, the residual cohesion first increased and then decreased. When the content was $1.5 \%$, the residual cohesion increased from $58.60 \mathrm{kPa}$ to $129.26 \mathrm{kPa}$, and the extent of increase was $120.6 \%$. Furthermore, when the aspect ratio was constant, as the content increased, the internal friction angle first increased and then decreased, but it was still higher than that of cement-stabilized sand. From the above analysis, it can be concluded that the variations in residual cohesion and cohesion were the same and both attained their maximum values under the same content and aspect ratio $(0.5 \%$ and $3: 1$, respectively). The internal friction angle and residual internal friction angle of cement-stabilized sand reinforced with the waste polyester fiber became stable in the range of $34^{\circ}-41^{\circ}$.

3.9. Failure Mode under the Effects of Content and Aspect Ratio. The macroscopic failure morphology of cementstabilized sand reinforced with waste polyester fiber blocks under the effects of content and aspect ratio is shown in Figure 12. It can be seen that the samples exhibited different degrees of dilatancy. When the confining pressure and fabric block content were low, the sample showed obvious brittle failure characteristics. The surface had connected and independent cracks, and the axial deformation was small at failure. As the confining pressure and content increased, the ductile failure characteristics of the sample became obvious. The sample surface had monoclinic or sparse conjugate cracks or a dense conjugate crack network, and the axial deformation increased at failure. Combined with the variation in the brittleness index, the macroscopic failure morphology and brittleness index of the sample could be used to evaluate the brittleness and ductility of cement-stabilized sand reinforced with waste polyester fiber fabric blocks qualitatively and quantitatively, respectively. A smaller brittleness index indicates more surface conjugate cracks or conjugate crack networks and higher ductility. 


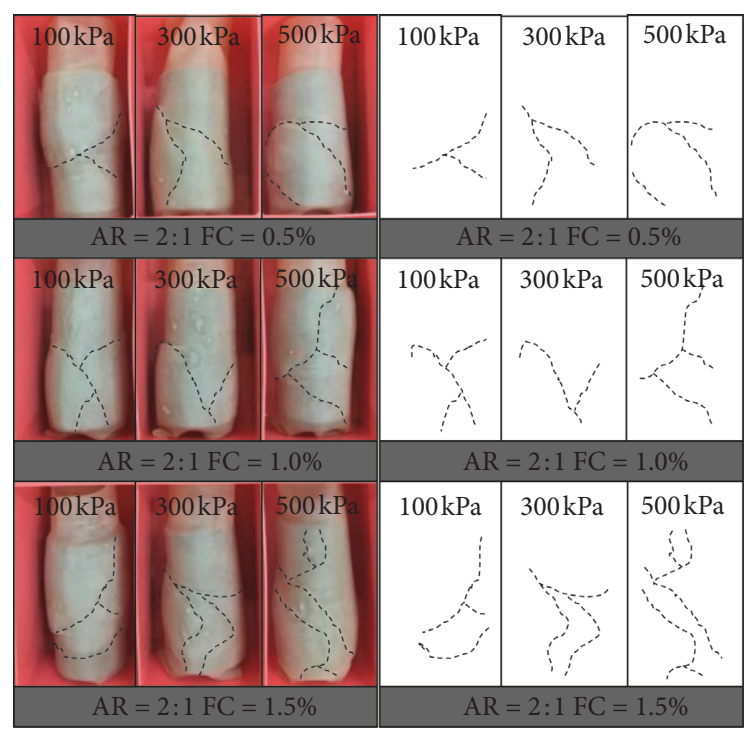

(a)

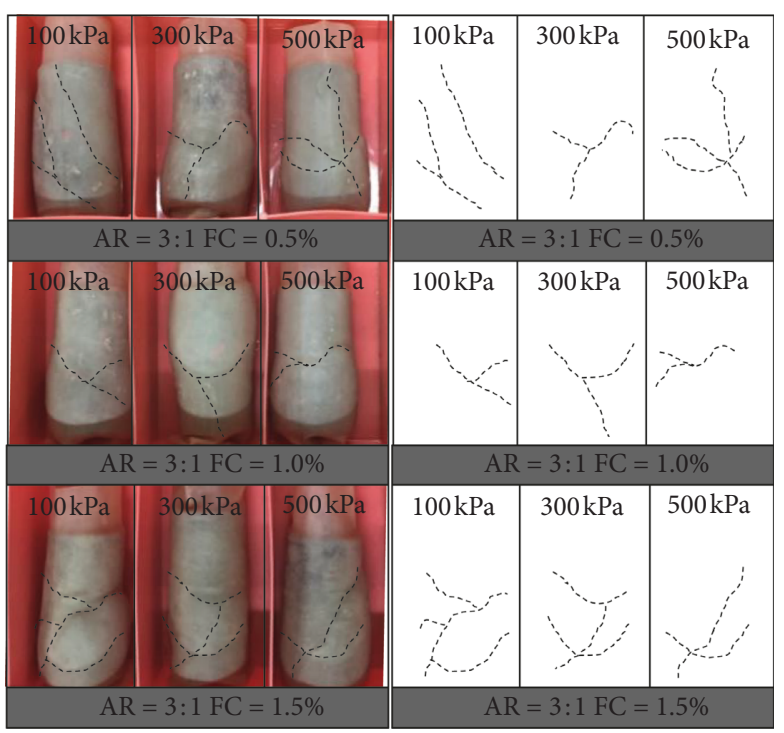

(b)

FIGURE 12: Macroscopic morphology of cement-stabilized sand reinforced with waste polyester fiber fabric blocks: (a) aspect ratio of $2: 1$; (b) aspect ratio of $3: 1$.

\subsection{Mesoscopic Reinforcement Effect of Waste Polyester Fiber Fabric Blocks on the Shear Characteristics of Cement-Stabilized Sand}

3.10.1. Integration of the Fabric Block with the CementStabilized Sand Matrix. The hydration process of cement in cement-stabilized sand is shown in Figures 13(a) and 13(b). The mesomorphology of the fabric blocks integrated with the cement-stabilized sand matrix is shown in Figure 13(c). It can be seen from Figure 13(a) that when curing was carried out for three days, there were bud-shaped hydrate products adhering to the surface of the sand particles and the voids between the particles were filled with crystals. Furthermore, it can be seen from Figure 13(b) that further growth of the crystals occurred when curing was carried out for 14 days. Floc-like and flaky hydrate products were generated (mainly calcium silicate hydrate $(\mathrm{C}-\mathrm{S}-\mathrm{H})$ and $\left.\mathrm{Ca}(\mathrm{OH})_{2}\right)$ [31], which overlapped and bonded with each other to further fill the voids between the sand particles. In addition, it can be seen from Figure 13(c) that, after the voids between the sand particles and the voids between the fabric blocks and the sand particles were filled with the hydrate products, the fabric blocks and sand particles were bonded together. The main component of a sand particle is silica, which will form colloidal particles of silicic acid upon contact with water. The equivalent adsorption exchange would occur between the sodium ions $\left(\mathrm{Na}^{+}\right)$and potassium ions $\left(\mathrm{K}^{+}\right)$on the surface of these colloidal particles and calcium ions $\left(\mathrm{Ca}^{2+}\right)$ in the calcium hydroxide formed from cement hydration. This will result in a large number of sand particles forming relatively large agglomerates. As a result of the agglomeration, the integration of the fabric blocks with the sand became more compact. Once the overall strength stabilized, the blocks could bear external load.
3.10.2. Influence of Interface Interactions on Shear Characteristics. The distribution pattern of fabric blocks in cement-stabilized sand is shown in Figure 14. Tang et al. [13] proposed two main types of interface interactions between fibers and the soil matrix: bonding and friction. According to Figures 13(c) and 14(a), in the present study, the interface bonding is mainly attributable to the bonding effect of the hydrate products of cement and the bonding between the cement crystals on the fabric block surface and the cement crystals in the sand. The interface friction is mainly attributable to the interlocking effect between the cement-stabilized sand matrix, the sand matrix, and the fabric blocks and the pressing and gripping between the sand particles and the fabric blocks. The interface bonding and interface friction together prevented the deformation and failure of the sample. The fabric blocks could also bear external load. Therefore, the shear performance of cementstabilized sand reinforced with waste polyester fiber fabric blocks was better than that of cement-stabilized sand, such that the shear strength, residual shear strength, and peak strain were large, while the postpeak stress loss was small. When the sample exhibited a shear dislocation surface or tensile crack under external load, the "bridge" effect of the fabric blocks could effectively prevent further development of tensile cracks and deformation of cement-stabilized sand (Figure 15(b)). Thus, cement-stabilized sand reinforced with the fabric blocks exhibited certain ductility such that the sample strain at failure increased and the brittleness index decreased. Some studies [32-34] have shown that the sliding resistance of the fibers is closely related to their roughness. The undulation between the monofilaments (Figure 14(b)) constituting the fabric blocks used in this study increased the roughness of the blocks, enhanced the interface interactions, improved the sliding resistance of 


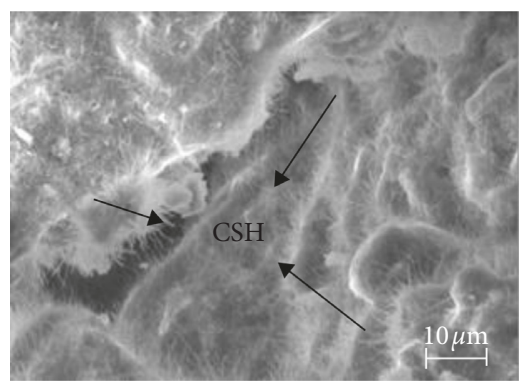

(a)

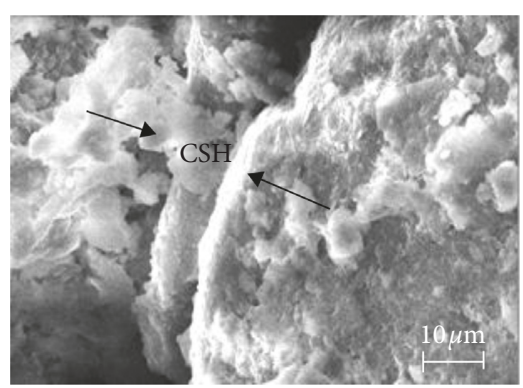

(b)

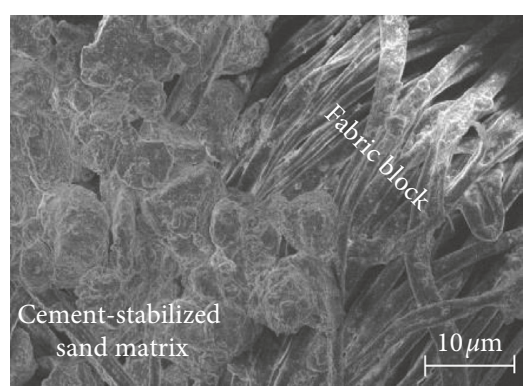

(c)

FIGURE 13: Cement hydration process and integration of fabric blocks with the cement-stabilized sand matrix: (a) curing for 3 days; (b) curing for 14 days; (c) mesomorphology after integration of fabric blocks with the cement-stabilized sand matrix.

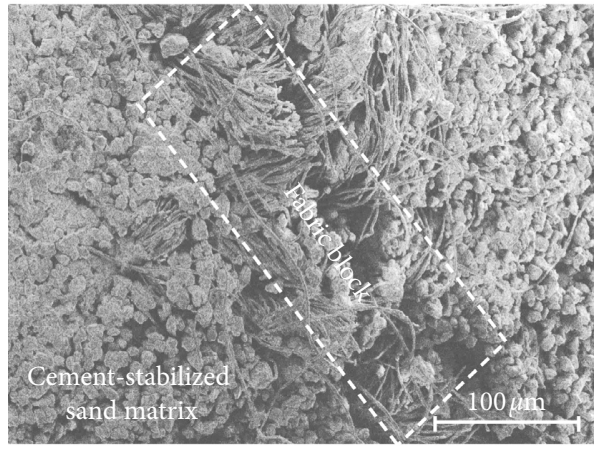

(a)

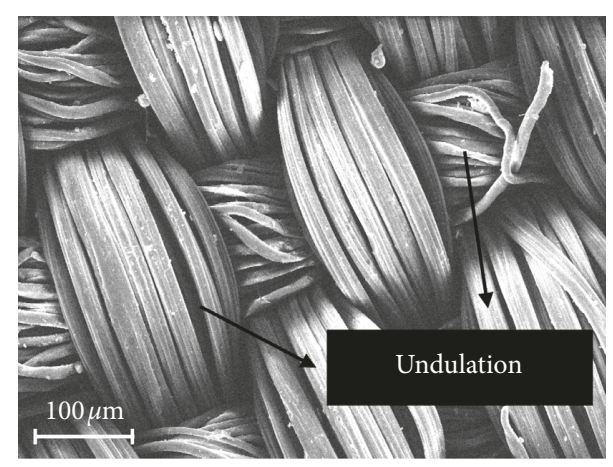

(b)

FIgURE 14: (a) Distribution pattern of fabric blocks in cement-stabilized sand; (b) surface morphology of fabric blocks.

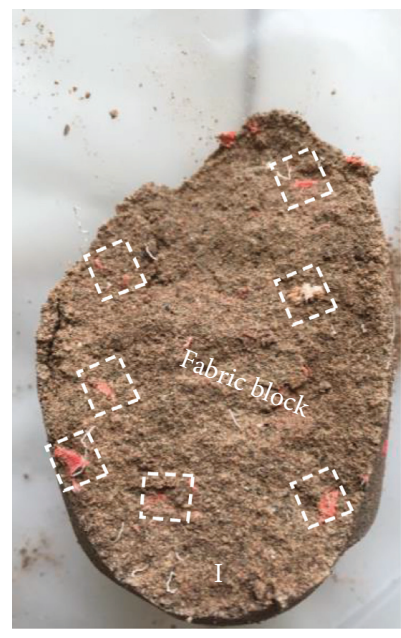

(a)

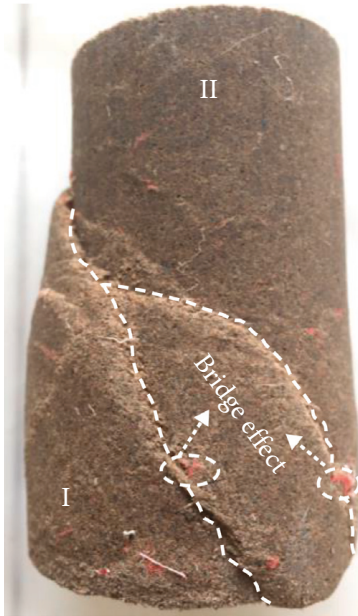

(b)

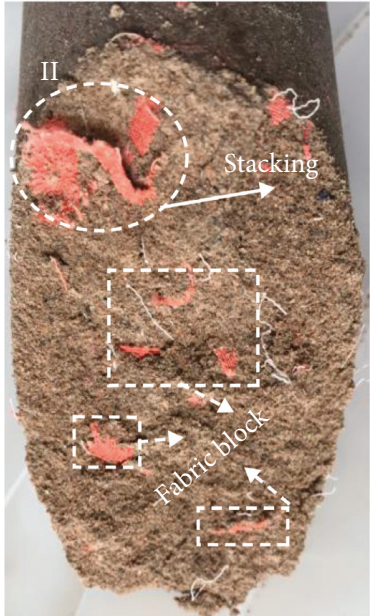

(c)

FiguRE 15: Shear failure surface morphology and distribution of fabric blocks on the failure surface: (a) shear failure surface-part I; (b) whole morphology of the sample after the shear failure; (c) shear failure surface-part II.

the blocks, and strengthened the reinforcement effect of the blocks.

3.10.3. Effects of Content and Aspect Ratio on Interface Interactions. The triaxial test results showed that when the aspect ratio was $2: 1$, as the content increased, the shear strength and cohesion increased, and when the aspect ratio was $3: 1$, as the content increased, the shear strength and cohesion first increased and then decreased. This was mainly because the fabric blocks were distributed randomly in the cement-stabilized sand, and when the aspect ratio was small, the increase in content would increase the contact area 
between the blocks and the cement-stabilized sand matrix, thereby increasing the interface interactions. When the aspect ratio increased and the content was too high, stacking of the blocks occurred (Figure 15(c)). As the bonding and friction between the blocks were weaker than those between the blocks and the cement-stabilized sand, the interface interactions weakened. Under shear stress, the blocks gathered together and the stacking area formed a potential shear slip surface. The sample finally underwent shear failure along this potential slip surface (Figures 15(a)-15(c)). As the content increased, the number of blocks that acted as a "bridge" increased and the "bridge" effect was enhanced such that the brittleness index decreased and the ductile failure characteristics became obvious (Figure 12).

\section{Conclusions}

In this study, a triaxial test and scanning electron microscopy were conducted to determine the effects of the waste polyester fiber fabric block content $(0.0 \%, 0.5 \%, 1.0 \%$, and $1.5 \%)$ and aspect ratio $(2: 1,3: 1)$ on the shear characteristics of cement-stabilized sand. The main conclusions are as follows:

(1) The addition of the waste polyester fiber fabric block to the cemented sand can increase the peak and residual shear strength and reduce the initial stiffness and brittleness index. The shear properties of fiberreinforced cement sands are related to the fiber content and aspect ratio. In the present study, an optimal combination of the fabric block aspect ratio and content was identified $(3: 1$ and $0.5 \%$, respectively). Under the optimal combination, the shear strength, residual shear strength, cohesion, residual cohesion, and energy absorption capacity all reached their maximum values.

(2) The SEM tests found that the reinforcement effect is related to the bond strength and friction at the interface. The micromechanical properties of the fiber/ matrix interface were influenced by the undulations between the fabric block components. The bridge effect of the fiber can efficiently impede the further development of cracks and deformation of the cemented sand.

(3) The macroscopic morphology after failure and the brittleness index of the sample could be used to evaluate the brittleness and ductility of fiber-reinforced cement-stabilized sand. A smaller brittleness index indicates more conjugate cracks on the failure surface and higher ductility.

(4) The significance of this study is that it presented an effective method for low-cost and environmentfriendly reinforcement of cement-stabilized sand by recycling waste polyester fibers. The effects of waste fiber fabric type, cement content, curing time, sand moisture content, dry density, particle size, etc., on the strength and deformation characteristics of cement-stabilized sand will be studied in the future.

\section{Data Availability}

The data used to support the findings of this study are available from the corresponding author upon request.

\section{Conflicts of Interest}

The authors declare that they have no conflicts of interest.

\section{Acknowledgments}

This work was supported by the National Natural Science Foundation of China (project numbers: 51504029 and 51774048) and Beijing Municipal Excellent Talents Foundation (project number: 2017000021223ZK04).

\section{References}

[1] M. A. Ismail, H. A. Joer, W. H. Sim, and M. F. Randolph, "Effect of cement type on shear behavior of cemented calcareous soil," Journal of Geotechnical and Geoenvironmental Engineering, vol. 128, no. 6, pp. 520-529, 2002.

[2] Y. T. Kim, H. J. Kim, and G. H. Lee, "Mechanical behavior of lightweight soil reinforced with waste fishing net," Geotextiles and Geomembranes, vol. 26, no. 6, pp. 512-518, 2008.

[3] H. Liu, A. Deng, and J. Chu, "Effect of different mixing ratios of polystyrene pre-puff beads and cement on the mechanical behaviour of lightweight fill," Geotextiles and Geomembranes, vol. 24, no. 6, pp. 331-338, 2006.

[4] N. C. Consoli, M. A. Vendruscolo, and P. D. M. Prietto, "Behavior of plate load tests on soil layers improved with cement and fiber," Journal of Geotechnical and Geoenvironmental Engineering, vol. 129, no. 1, pp. 96-101, 2003.

[5] N. C. Consoli, M. A. Vendruscolo, A. Fonini, and F. D. Rosa, "Fiber reinforcement effects on sand considering a wide cementation range," Geotextiles and Geomembranes, vol. 27, no. 3, pp. 196-203, 2009.

[6] N. C. Consoli, R. R. de Moraes, and L. Festugato, "Parameters controlling tensile and compressive strength of fiber-reinforced cemented soil," Journal of Materials in Civil Engineering, vol. 25, no. 10, pp. 1568-1573, 2013.

[7] L. Festugato, A. Fourie, and N. C. Consoli, "Cyclic shear response of fibre-reinforced cemented paste backfill," Géotechnique Letters, vol. 3, no. 1, pp. 5-12, 2013.

[8] L. Festugato, A. P. da Silva, A. Diambra, N. C. Consoli, and E. Ibraim, "Modelling tensile/compressive strength ratio of fibre reinforced cemented soils," Geotextiles and Geomembranes, vol. 46, no. 2, pp. 155-165, 2018.

[9] A. Hamidi and M. Hooresfand, "Effect of fiber reinforcement on triaxial shear behavior of cement treated sand," Geotextiles and Geomembranes, vol. 36, pp. 1-9, 2013.

[10] S. R. Kaniraj and V. G. Havanagi, "Behavior of cement-stabilized fiber-reinforced fly ash-soil mixtures," Journal of Geotechnical and Geoenvironmental Engineering, vol. 127, no. 7, pp. 574-584, 2001.

[11] S.-S. Park, "Effect of fiber reinforcement and distribution on unconfined compressive strength of fiber-reinforced cemented sand," Geotextiles and Geomembranes, vol. 27, no. 2, pp. 162-166, 2009.

[12] S. K. Saman and J. C. Asskar, "Triaxial behavior of fiberreinforced cemented sand," Journal of Adhesion Science and Technology, vol. 30, no. 6, pp. 579-593, 2016. 
[13] C. Tang, B. Shi, W. Gao, F. Chen, and Y. Cai, "Strength and mechanical behavior of short polypropylene fiber reinforced and cement stabilized clayey soil," Geotextiles and Geomembranes, vol. 25, no. 3, pp. 194-202, 2007.

[14] L. Gao, G. H. Hu, Y. H. Chen, Y. J. Hu, and Y. H. Gong, "Triaxial tests clay reinforced by basalt fiber," Chinese Journal of Geotechnical Engineering, vol. 39, no. 1, pp. 198-203, 2017.

[15] M. Chen, S.-L. Shen, A. Arulrajah, H.-N. Wu, D.-W. Hou, and Y.-S. Xu, "Laboratory evaluation on the effectiveness of polypropylene fibers on the strength of fiber-reinforced and cement-stabilized Shanghai soft clay," Geotextiles and Geomembranes, vol. 43, no. 6, pp. 515-523, 2015.

[16] A. R. Estabragh, P. Namdar, and A. A. Javadi, "Behavior of cement-stabilized clay reinforced with nylon fiber," Geosynthetics International, vol. 19, no. 1, pp. 85-92, 2012.

[17] M. Mirzababaei, M. Miraftab, M. Mohamed, and P. McMahon, "Unconfined compression strength of reinforced clays with carpet waste fibers," Journal of Geotechnical and Geoenvironmental Engineering, vol. 139, no. 3, pp. 483493, 2013.

[18] L. T. Cao, H. L. Ren, J. H. Zuo, and Q. L. Du, "Mechanical properties of textile fiber modified clay," Journal of Building Materials, vol. 17, no. 1, pp. 110-114, 2014.

[19] Y. Liu, Y. Zhang, Y. Guo, P. K. Chu, and S. Tu, "Porous materials composed of flue gas desulfurization gypsum and textile fiber wastes," Waste and Biomass Valorization, vol. 8, no. 1, pp. 203-207, 2017.

[20] ASTM C187, Standard Test Method for Amount of Water Required for Normal Consistency of Hydraulic Cement Paste, ASTM International, West Conshohocken, PA, USA, 2010.

[21] ASTM C150, Standard Specification for Portland Cement, Annual Book of ASTM Standards. ASTM, Philadelphia, PA, USA, 2007.

[22] ASTM C109, Standard Test Method for Compressive Strength of Hydraulic Cement Mortar, ASTM International, West Conshohocken, PA, USA, 2016.

[23] ASTM C190-85, Standard Test Method for Tensile Strength of Hydraulic Cement Mortars, ASTM International, West Conshohocken, PA, USA, 1985.

[24] ASTM D2256, Standard Test Method for Tensile Properties of Yarns by the Single-Strand Method, ASTM International, West Conshohocken, PA, USA, 2008.

[25] ASTM D2101, Test Method for Tensile Properties of Single Man-Made Textile Fiber Taken from Yarns and Tows, ASTM International, West Conshohocken, PA, USA, 1994.

[26] A. Abou Diab, S. S. Najjar, S. Sadek, H. Taha, H. Jaffal, and M. Alahmad, "Effect of compaction method on the undrained strength of fiber-reinforced clay," Soils and Foundations, vol. 58, no. 2, pp. 462-480, 2018.

[27] ASTM D1632, Standard Practice for Making and Curing Soil-Cement Compression and Flexure Test Specimens in the Laboratory, ASTM International, West Conshohocken, PA, USA, 2017.

[28] T. Namikawa, S. Hiyama, Y. Ando, and T. Shibata, "Failure behavior of cement-treated soil under triaxial tension conditions," Soils and Foundations, vol. 57, no. 5, pp. 815-827, 2017.

[29] C. Gu, J. Wang, Y. Cai, L. Sun, P. Wang, and Q. Y. Dong, "Deformation characteristics of overconsolidated clay sheared under constant and variable confining pressure," Soils and Foundations, vol. 56, no. 3, pp. 427-439, 2016.

[30] N. C. Consoli, P. D. M. Prietto, and L. A. Ulbrich, "Influence of fiber and cement addition on behavior of sandy soil,"
Journal of Geotechnical and Geoenvironmental Engineering, vol. 124, no. 12, pp. 1211-1214, 1998.

[31] Y. Yi, X. Zheng, S. Liu, and A. Al-Tabbaa, "Comparison of reactive magnesia- and carbide slag-activated ground granulated blastfurnace slag and Portland cement for stabilisation of a natural soil," Applied Clay Science, vol. 111, pp. 21-26, 2015.

[32] J. D. Frost and J. Han, "Behavior of interfaces between fiberreinforced polymers and sands," Journal of Geotechnical and Geoenvironmental Engineering, vol. 125, no. 8, pp. 633-640, 1999.

[33] S. P. Shah, "Do fibers increase the tensile strength of cementbased matrix?," ACI Materials Journal, vol. 88, no. 6, pp. 595-602, 1991.

[34] A. Tagnit-Hamou, Y. Vanhove, and N. Petrov, "Microstructural analysis of the bond mechanism between polyolefin fibers and cement pastes," Cement and Concrete Research, vol. 35, no. 2, pp. 364-370, 2005. 


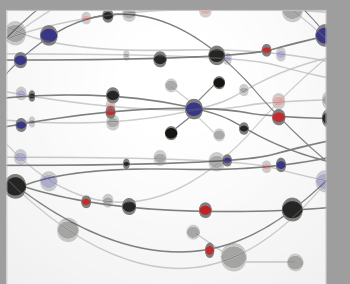

The Scientific World Journal
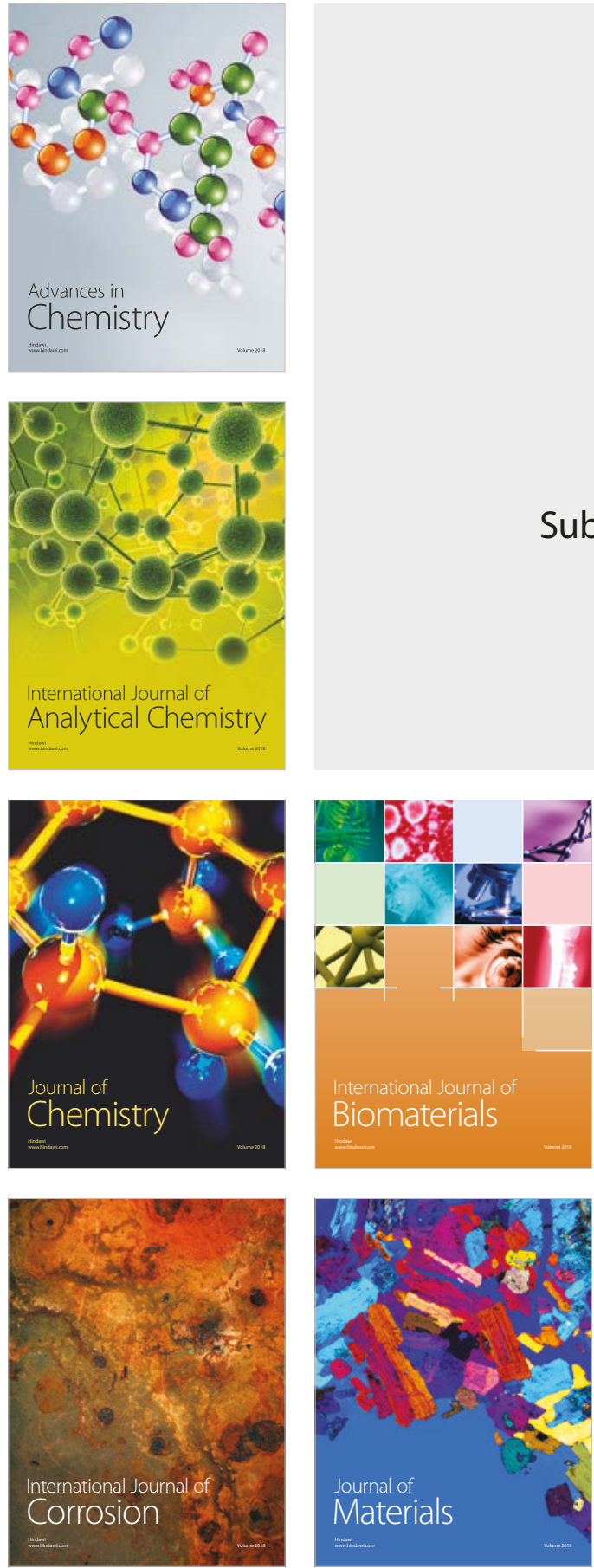

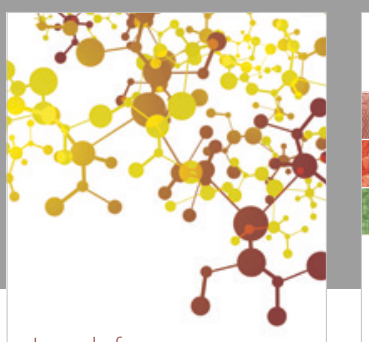

Journal of

Applied Chemistry
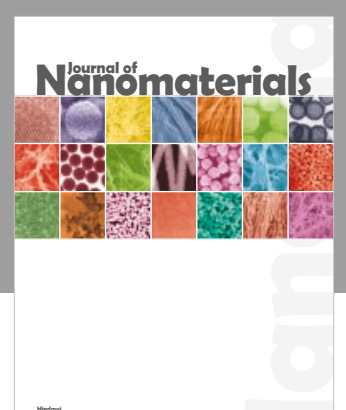

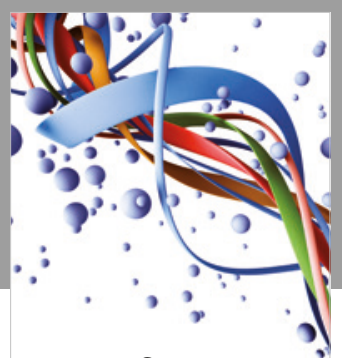

Scientifica

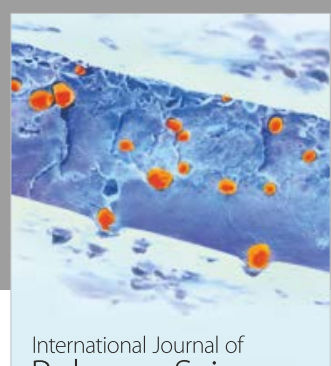

Polymer Science

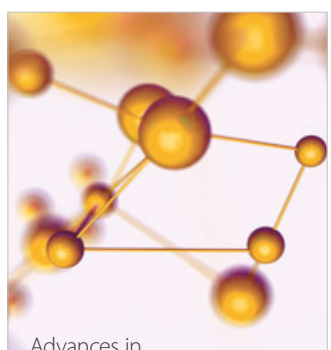

Physical Chemistry
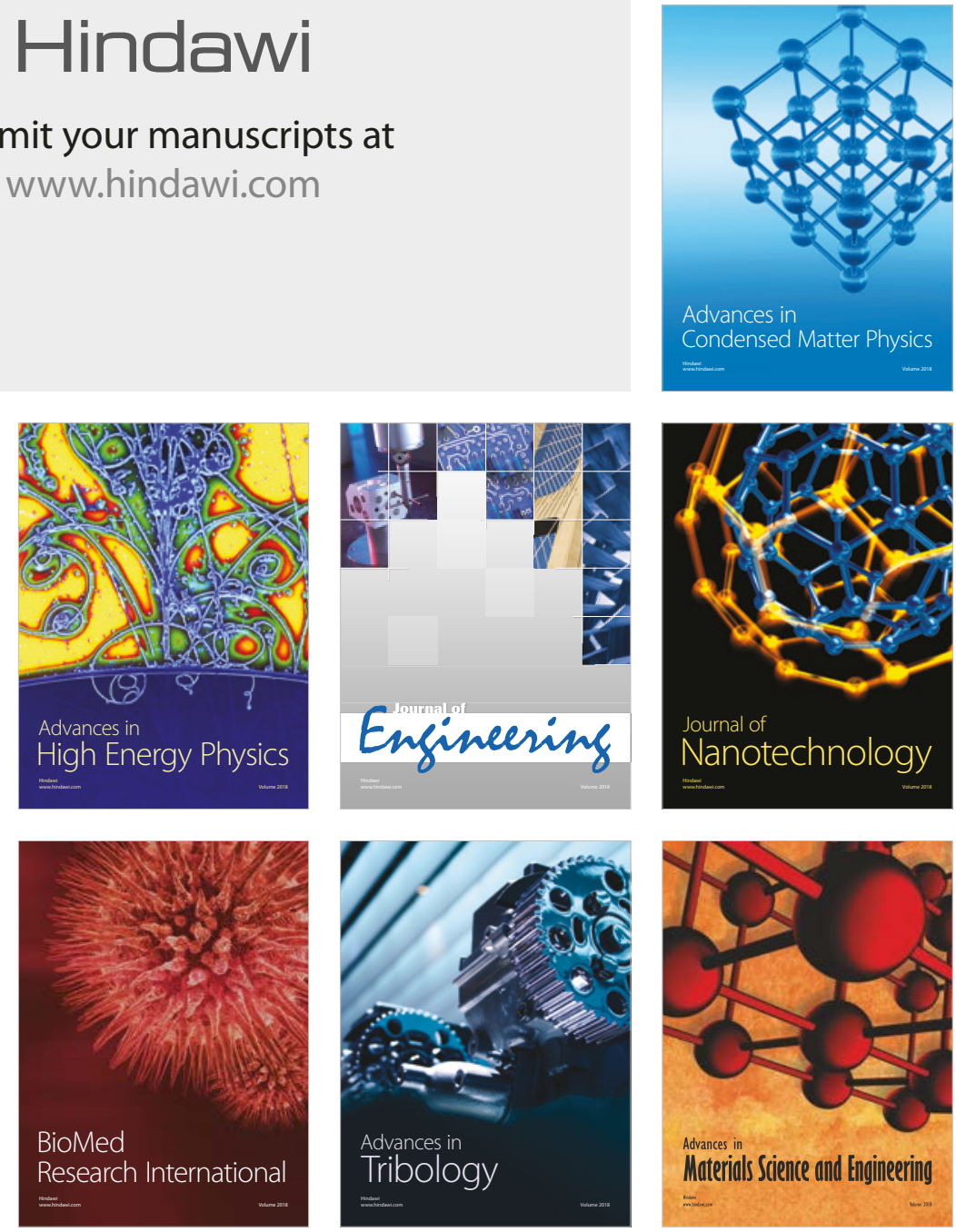